\title{
In search of durable positive psychology interventions: Predictors and consequences of long-term positive behavior change
}

\author{
Michael A. Cohnn ${ }^{a,}$ and Barbara L. Fredrickson ${ }^{b}$ \\ aOsher Center for Integrative Medicine, University of California, 1701 Divisadero Street, Suite \\ 150, San Francisco, CA 94118, USA \\ bepartment of Psychology, University of North Carolina, Davie Hall, Campus Box 3270, Chapel \\ Hill, NC 27599-3270, USA
}

\begin{abstract}
A number of positive psychology interventions have successfully helped people learn skills for improving mood and building personal resources (e.g., psychological resilience and social support). However, little is known about whether intervention activities remain effective in the long term, or whether new resources are maintained after the intervention ends. We address these issues in a 15-month follow-up survey of participants from a loving-kindness meditation intervention. Many participants continued to practice meditation, and they reported more positive emotions (PEs) than those who had stopped meditating or had never meditated. All participants maintained gains in resources made during the initial intervention, whether or not they continued meditating. Continuing meditators did not differ on resources at baseline, but they did show more $\mathrm{PE}$ and a more rapid PE response to the intervention. Overall, our results suggest that positive psychology interventions are not just efficacious but of significant value in participants' real lives.
\end{abstract}

\section{Keywords}

positive emotions; interventions; broaden-and-build; meditation; loving-kindness; adherence; long-term effects; positive emotion reactivity

\section{Introduction}

How do people lastingly change their lives for the better? Research shows that many people are willing and able to learn methods for self-generating positive emotions (PEs), including skills, such as loving-kindness meditation (LKM) (Fredrickson, Cohn, Coffey, Pek, \& Finkel, 2008), savoring and gratitude (Emmons \& McCullough, 2003; Sheldon \& Lyubomirsky, 2006), cognitive reframing (Seligman, Rashid, \& Parks, 2006; Seligman, Steen, Park, \& Peterson, 2005), acts of kindness toward others (Tkach \& Lyubomirsky, 2005, 2007), and active-constructive responding to others' good fortune (Seligman et al., 2005). Some of these interventions have produced benefits beyond PEs, such as improved physical health (Emmons \& McCullough, 2003), reduced subclinical symptoms of depression and illness (Fredrickson et al., 2008), and reduced risk of clinical depression (Seligman et al., 2006). In this article, we report a one-year follow-up of a large, successful 
trial of LKM training to answer important questions about whether these interventions can have long-term effectiveness and appeal.

Experimental findings on PE interventions are consistent with a larger body of prospective correlational research, which has found that PEs predict many desirable short- and long-term outcomes. These outcomes include mental health (Epping-Jordan et al., 1999; Fredrickson \& Joiner, 2002), successful coping (Moskowitz, Folkman, \& Acree, 2003), and closer relationships (Harker \& Keltner, 2001; Waugh \& Fredrickson, 2006). PEs also prospectively predict physical health and longevity in both healthy individuals and those with chronic illness (Levy, Slade, Kunkel, \& Kasl, 2002; Markland, Pressman, \& Cohen, 2006; Moskowitz, Epel, \& Acree, 2008; Ong \& Allaire, 2005). All these findings remain true when taking the present circumstances into account (i.e., PEs often precede improved outcomes - the statistics do not simply reflect people who are doing better, and are happy about it).

We propose that the diverse benefits of PEs, whether naturally occurring or formally selfgenerated, can be understood through the framework of the broaden-and-build theory of Positive emotions (Cohn \& Fredrickson, 2009; Fredrickson, 1998, 2001). This theory suggests that PEs momentarily broaden attention, cognition, and behavioral repertoires, and that recurrence of these broadened states helps people gradually develop lasting and consequential personal resources (Cohn \& Fredrickson, 2009; Fredrickson, 1998). The broadened awareness created by PEs may help participants recognize the value of the new behaviors presented by positive psychology interventions, and broadened thought-action repertoires may help them integrate these new behaviors into their daily lives. As participants build new resources for coping with problems or capitalizing on opportunities, they increase their trait-like propensity for experiencing PEs in daily life, which in turn brings broadened awareness that makes future changes in behavior easier and more likely (Cohn, Fredrickson, Brown, Mikels, \& Conway, 2009; Fredrickson \& Joiner, 2002).

We recently conducted a randomized controlled trial (RCT) of LKM, a meditative practice that helps individuals evoke and intensify internal feelings of love, compassion, and other PEs (Fredrickson et al., 2008). This RCT is one of the few to causally link increases in PEs to improvements in mental health, physical health, and life satisfaction and the only trial to gather daily emotion data. Although participants' training involved varied behavioral, social, and cognitive components, these daily emotion reports indicated that LKM led to improved outcomes only when it generated PEs.

In this study, we contacted the participants 15 months after the final assessment, and again collected data on emotions, resources, and meditation practice. Our follow-up study is among the longest yet performed, and was carried out with no advance warning to participants and no communication in the interim. It allows us to explore what happens to the changes participants have undergone when they are 'released' back into everyday life.

\section{The current study}

A major purpose of this follow-up study was to determine whether any participants continued to meditate after the end of the intervention, and if so, whether meditation continued to produce PEs for them. Many pleasurable experiences fade over time as people come to take them for granted (Lyubomirsky, Sheldon, \& Schkade, 2005; Parducci, 1995), a pattern of emotional adaptation described as the 'hedonic treadmill' (Diener, Lucas, \& Scollon, 2006). In sharp contrast to a pattern of hedonic adaptation, we found that LKM actually increased its effectiveness over the two months of the original study, as evidenced by a tripling of the dose-response relationship between time spent on meditation and its PE yield (Fredrickson et al., 2008). 
We also examined the durability of the intervention's benefits. For participants who did not continue practicing the intervention skills, did their emotions and resources backslide to baseline levels? The broaden-and-build theory emphasizes that the resources built via PEs are durable. A person who is expansive and generous during a time of joy will have social resources to draw on later, when they are struggling. One who takes time for an idle chat with neighbors might learn about an unexpected job opportunity, a great new restaurant, or a home remedy they used when their dog was sprayed by a skunk. These resources (in this case, relationships, skills, and knowledge) are far more stable and long lasting than emotional experiences, and can be practiced and put to use regardless of one's current mood. Thus, we hypothesized that individuals who had built resources during the initial intervention would maintain the same resource levels at follow-up, even if they were no longer meditating and no longer experiencing elevated PEs. This would provide evidence that PE interventions can lead to durable personal resources, and not just to transient mood effects.

Finally, we investigated baseline predictors of continued practice. Knowing what makes participants more likely to continue practicing their new skills could help us support participants in future interventions, or match them to specific interventions that are wellsuited to them. Using our follow-up data, we were able to look backward: Did participants who went on to become continued meditators show any commonalities in their baseline characteristics or their experience during the original intervention period?

We hypothesized the following at one-year follow-up:

(1) LKM practice would remain an effective source of PEs. Specifically:

(a) more participants would have an ongoing meditation practice than at the beginning of the study and

(b) ongoing meditation would continue to predict PEs.

(2) Participants would retain resources gained during the initial intervention even if they later stopped meditating.

(3) Baseline PEs, baseline resources, and/or PEs evoked by the intervention would predict who continued to meditate.

\section{Method}

\section{Participants}

In the original LKM intervention study, 202 participants were recruited, 166 completed the final assessment, and 148 agreed to be recontacted for follow-up research. Ninety-five of these participants (64\%) were contacted and agreed to participate in the present follow-up study, 45 from the experimental group and 50 from the waitlist control group. Although waitlist participants had the opportunity to take the LKM classes approximately 3 months after the end of the study, they did so at a much lower rate than the meditation group participants (95.5\% of meditation group participants attended at least three workshop sessions, compared to $54 \%$ of waitlist participants, $\left.\chi^{2}(1, n=95)=21.1, p<0.001\right)$.

Median age for follow-up participants was 41 years $(M=42.2, \mathrm{SD}=9.7)$. Participants were predominantly White $(81.1 \%)$ or Asian (6.3\% East Asian, 9.5\% South Asian) and nonHispanic (98.9\%); 61.1\% were females. Because participants were recruited from an information technology company, educational level and socioeconomic status were high: most had a bachelor's or master's degree (77.9\%) and made over $\$ 85,000$ per year $(58.2 \%)$. 
Participants received $\$ 10$ for completing the follow-up survey and an additional $\$ 10$ if they responded to the daily questionnaire on at least 3 of the next 7 days.

Follow-up respondents were representatives of the original study sample. There were no significant differences in sex, education, income, marital status, age, or national origin ( $p>$ 0.17). The proportion of Black participants decreased relative to other racial categories $\left(\chi^{2}=12.64, p=0.01\right)$; there were no other racial or ethnic differences. Respondents did not differ from the original sample on group assignment, pre-intervention life satisfaction and depression, or final life satisfaction and depression.

Follow-up respondents and non-respondents reported similar levels of PEs during the 9 weeks of the initial study $\left(F_{\text {follow-up }}=1.00, p=0.32\right.$ ). Unexpectedly, week-by-week PEs were $=$ predicted by an interaction between respondent status and initial condition assignment: Meditators who responded to the follow-up had shown higher PE during the initial study than other meditators, while waitlist participants who responded to the follow-up had been lower on $\mathrm{PE}$ ( $\left.F_{\text {condxfollow-up }}=11.08, p=0.001\right)$. It is possible that participants were inclined to respond to the follow-up if they felt they had confirmed our expectations, meaning that we would have an overrepresentation of those who did well while receiving the intervention, or who did poorly while not receiving the intervention.

\section{Procedure}

Participants from the initial meditation study who had given permission for us to recontact them received an e-mail describing the follow-up study and compensation for participating. Prior to this, they had not received any indication that a follow-up was planned. The e-mail linked to the study website, which provided informed consent information and, for those who agreed to participate, administered the first set of questionnaires (described below).

The final page informed participants that we were interested in collecting daily reports from them on behavior and emotions, for additional compensation. They could opt to receive daily reminder e-mails, to participate without reminders, or to end their participation. They then provided contact information for receiving payment, and were debriefed and thanked.

The daily questionnaire was accessible to each participant for 7 days beginning the day after they submitted the follow-up questionnaires. It was a single-page form with questions about that day's emotional experience, whether they had meditated, and if so, the form and duration of the meditation.

\section{Measures}

The resources discussed here were measured on three occasions: The baseline assessment from the original LKM intervention study (T1), the final assessment, 2 months later (T2), and the current follow-up, 15 months after the final assessment (T3). Note that T2 occurred after LKM training for the experimental group, but before training for the waitlist control group. Thus, within-subject analyses that compare the effects of LKM training at T2 and T3 use only the experimental group $(n=45)$.

\section{Resources}

Participants completed measures on a subset of the social and psychological resources that were measured before and after the original intervention. The resources assessed were (1) mindfulness/mindlessness, (2) psychological well-being and social well-being, (3) hope, (4) ego-resilience, (5) savoring, (6) social support received and given, (7) self-other overlap with a close other, (8) symptoms of illness, and (9) life satisfaction. Table 1 shows a more detailed listing of each construct and the associated measures. 
After completing the questionnaires, participants answered questions about whether they had a current meditation practice and the extent to which they had participated in the LKM workshop when it was offered (this was our only source of information on workshop attendance among waitlist participants).

\section{Daily questionnaires}

Participants responded to these questions every day for 1 week following the T3 assessment.

Modified Differential Emotions Scale-Modified Differential Emotions Scale (mDES) (Fredrickson, Tugade, Waugh, \& Larkin, 2003) names 19 specific emotions and asks participants to recall their strongest experience of each emotion over the past $24 \mathrm{~h}$ (which is recalled more accurately than average or typical levels; Fredrickson \& Kahneman, 1993). Participants rated each emotion on a 5-point scale (1=not at all, 5=extremely). The PEs subscale consisted of amusement, awe, contentment, gratitude, hope, joy, interest, love, and pride; the negative emotions subscale consisted of anger, contempt, disgust, embarrassment, guilt, sadness, shame, and fear. The subscales had good internal reliability (average $\alpha_{\mathrm{PE}}=0.94, \alpha_{\mathrm{NE}}=0.82 ; \mathrm{NE}$, negative emotion). Two additional emotions, surprise and compassion, were assessed but did not group with positive or negative emotions, either theoretically or in factor analysis, so they were not analyzed. Only participants who responded on at least 3 of the 7 days were given aggregate scores on this measure.

Meditation practice-Participants reported whether they had engaged in `meditation, prayer, or solo spiritual activity' in the last $24 \mathrm{~h}$ or, on subsequent days, in the time since their last report. They were asked to describe the meditative activity they had engaged in and its approximate duration (in minutes).

\section{Results}

\section{H1a: Do participants continue to meditate?}

Participants reported how frequently they had been meditating since the end of training, using the options 'no,' 'a few times,' 'occasionally,' 'frequently,' and 'nearly every day.' Thirty-three participants (34.7\%) reported meditating 'occasionally' or more often. Their daily questionnaire responses corroborated these reports: participants meditating 'occasionally' reported an average of $5.9 \mathrm{~min} /$ day of formal meditation, 'frequent' participants reported $28.4 \mathrm{~min} /$ day, and 'daily' participants reported $35.2 \mathrm{~min} /$ day.1

Continuers and non-continuers did not differ on any demographic characteristic ( $p$ for $\chi^{2}$ test $>0.08)$ or on initial condition assignment $\left(\chi^{2}(1, n=95)=0.07, p=0.79\right)$. Among continuers, $37 \%$ continued to practice LKM, 37\% practiced a different form of meditation, and $26 \%$ practiced both LKM and another type.

Prior to the intervention, eight of the original 202 participants (3.9\%) reported meditating. In the follow-up sample, 33 of the 95 participants (34.7\%) meditated. Because continuing meditators might have been more likely to respond to the follow-up, we analyzed the results based on a worst-case scenario: All non-respondents were treated as non-meditators, leading to an estimate of 33/202 (16.3\%) of the sample becoming continued meditators. The increase is significant $\left(\chi^{2}(1, n=202)=81.3, p<0.001\right)$, indicating that the intervention increased the number of participants who practiced meditation, even more than 1 year after

\footnotetext{
${ }^{1}$ Participants who did not take part in the meditation workshop showed results that are very similar to those who did participate, and did not continue to meditate. These two groups are combined under 'non-continuers.' One participant, who did not participate but who did have a meditation practice at follow-up, is included under 'continuers.' Excluding this participant has negligible effects on the results presented in this article.
} 
its completion. Our conservative analysis rules out the possibility that this conclusion results from response bias.

\section{H1b: Does meditation continue to predict PEs?}

Continuing meditators reported more PEs in their daily reports at T3 (follow-up) than did non-continuers $(F(1,65)=12.11, p=0.001)$. The groups did not differ in how much their PE changed over the 15 months between T2 and T3 $\left(F_{\text {timexgroup }}(1,43)=1.99, p=0.17\right)$, though continuers were higher at both points $\left(F_{\text {group }}(1,43)=17.89, p<0.001\right)$.

PEs also correlated positively with number of minutes spent meditating per day $(r(67)=0.25$, $p=0.04$ ). When we normalized the time by $\log$ transforming, the correlation remained similar, but became non-significant (likely due to reduced power, because log transforming required removing all zero values; $r(36)=0.21, p=0.22)$.

\section{H2: Are resources lost when meditation ceases?}

We hypothesized that the resources participants built through meditation would remain available, even if meditation ceased. Because the waitlist group did not complete an immediate post-training assessment, only participants from the original meditation condition could be used to test this hypothesis.

We calculated the difference scores for each resource between $\mathrm{T} 1$ and $\mathrm{T} 2$ and between $\mathrm{T} 2$ and $\mathrm{T} 3$, and then tested regression models in which $\mathrm{T} 2-\mathrm{T} 3$ difference is predicted by T1-T2 difference, continued meditation, and the interaction between the two. The construction of the change variables causes them to correlate negatively, but a positive interaction coefficient would indicate that the relationship is more negative for participants who stopped meditating - that is, those who built resources tended to lose them after meditation ceased. The interaction coefficients were small and non-significant: The average $\beta$ was 0.12 , several were between 0.2 and 0.3 , and only psychological well-being had $\beta>0.3$ or $p<0.2$. There was also no suggestion that increases in daily PEs were lost after ceasing to meditate $(\beta<19$, $p>0.29$ ).

Further examination of the data suggested that resource levels of the non-continuers may not have dropped primarily because they never rose in the first place - participants who would, later on, not continue to meditate showed noticeably smaller gains in resources than those who would. Post-hoc tests of this relationship are non-significant for most resources, but nearly all trend in the same direction: those who would continue meditating built more resources during the initial intervention than those who would not. Even if this difference occurred by chance, it limits the potential for the dataset to demonstrate resource backsliding among non-continuers. In sum, the data are clearly consistent with our hypothesis that resources gained during the intervention would persist with or without continued practice. However, they do not offer strong empirical grounds for rejecting the alternative hypothesis that non-continuers would lose resources.

\section{H3: Do resources and PEs predict continued meditation?}

Our hypothesis that $\mathrm{T} 1$ resources would predict continued meditation was unsupported. Participants who would continue meditating started out higher only on social support given $(F(1,93)=3.87 p=0.05)$ and, marginally, on social support received $(F(1,93)=3.31, p=0.07)$. Because these were embedded among 10 non-significant results, they could easily reflect alpha inflation. In contrast, daily PE assessments during the baseline week of the original study did predict continued meditation $(F(1,92)=5.79 p=0.02, \eta=0.24)$. Prior to learning LKM, those who would continue meditating were already reporting higher PEs. 
Waitlist group participants did not provide any emotion data during or after their meditation training, so analyses of pre- to post-training PEs must be restricted to the original meditation group. The finding that continued meditators had been higher on baseline PE did not remain significant when assessed only in this group $(F=1.20, p=0.28)$. Within this group, continuers and non-continuers also did not differ on change in PE over time (fixed effects linear mixed model, $t_{\text {timexcond }}=1.16, p=0.24$ ).

However, inspection of the data suggested that non-continuers only began to show elevated PE during the last 3 weeks of the intervention (Figure 1). When we added a dummy variable distinguishing the period between baseline and week 5 from the period between weeks 6 and 8 , we found the expected 3-way interaction $\left(t_{\text {continuer }} \times\right.$ late-week $\left.=1.96, p=0.05\right)$ : Those who would continue meditating experienced increased PEs immediately, whereas those who would cease meditating did not experience increases in PEs until week 6. The 2-way interaction between continued meditation and week became significant as well $(t=2.38$, $p=0.02$ ). Although we did not find the predicted effect of PE reactivity on continued meditation, the data strongly suggest that early reactivity does predict continuation.

This difference in response profiles was not caused by differential effort or participation. Continuers and non-continuers did not differ on class attendance or time spent practicing, even during the final week when formal training had ended and meditation practice was selfgoverned.

To illustrate the strength of this finding, we performed a series of logistic regression analyses using different $\mathrm{PE}$ indices to predict continuer/ non-continuer status. Consistent with the findings above, baseline PE was not a significant predictor (odds ratio (OR) 95\% CI $=0.62-5.51, p=0.28)$, and the variance it explained was minimal $\left(\mathrm{R}^{2} \leq 0.04\right)$. Total increase in $\mathrm{PE}$ (week $8 \mathrm{PE}$ controlling for baseline $\mathrm{PE}$ ) was a significant predictor $(\mathrm{OR}=1.02-7.36$, $p=0.05, \mathrm{R}^{2}=0.18$ ). However, when week $5 \mathrm{PE}$ is added to the regression, baseline and week $8 \mathrm{PE}$ become non-significant (OR $0.23-5.73, p \geq 0.39$ ), whereas week $5 \mathrm{PE}$ is significant, and the total variance explained is greatly increased $\left(\mathrm{OR}=1.73-100.72, p=0.01, \mathrm{R}^{2}=0.44\right)$. This suggests that week $5 \mathrm{PE}$ is a good predictor of whether an individual will continue to meditate, but change from weeks 5 to 8 contributes very little.

The overall predictive power of early PE is quite large. In practical terms, an individual 1 standard deviation above the mean on early PE reactivity 2 was twice as likely to continue meditating as one with average reactivity, and $\sim 4.5$ times as likely as one who was 1 standard deviation below the mean.

\section{Discussion}

Many participants in our LKM intervention continued to meditate, to experience enhanced PEs, and to maintain increased personal resources, even more than one year after the end of training. This is powerful evidence that skills-based positive psychology interventions can remain enjoyable and effective long after formal training has ended.

Just as importantly, individuals who completed the intervention but did not continue to practice LKM maintained any resources they had built. This indicates that positive psychology interventions can be a valuable investment for many participants, not just the subset that continues to practice. This finding is also consistent with the broaden-and-build theory of positive emotions, which proposes that PEs are adaptive in part because they help

\footnotetext{
2 In order to present a model that can be expressed more intuitively, we reduced the two predictors used in the previous paragraph to one: a raw difference score between week 5 and baseline. This does not change the results $(\mathrm{OR}=1.54-21.24, p=0.01)$, though it reduces the effect size $\left(R^{2}=0.27\right)$.
} 
build enduring resources. We note, however, that this dataset was not ideal for testing this hypothesis, and future research is needed before it can be considered strongly supported.

Finally, we discovered a potential marker for long-term intervention adherence: early positive emotional reactivity. Participants who showed a rapid increase in PEs after starting the intervention were more likely to continue meditating a year later. Other participants practiced just as diligently, even during the week after the end of formal training, and by the end of the study were also experiencing increased PEs. Nonetheless, they were less likely to continue meditating the following year. If this same pattern is found in other positive psychology interventions, it could provide a valuable marker of whether an individual is 'connecting' with the intervention and likely to continue with it.

\section{Long-lasting PE skills}

One year after the end of the meditation intervention, the number of participants who practiced meditation remained significantly elevated. Over half of these meditators had adopted another form of meditation, commonly prayer or personal reflection, in place of or alongside LKM. This heterogeneity reduces our ability to draw focused conclusions about the effects of continued LKM practice, but it indicates that the LKM intervention as a whole is adaptable to personal needs and preferences and has robust, lasting effects.

This kind of adaptability may be an important common factor in effective positive psychology interventions, which often encourage participants to choose from among a variety of techniques (e.g., Moskowitz et al., under review; Seligman et al., 2006). Different individuals may need different practices, depending on culture, circumstances, and personal preference. Additionally, the act of choosing may increase the individual's sense that their practice is voluntary and intrinsically motivated, which is linked to greater persistence and adherence (Deci \& Ryan, 2000; Ryan \& Deci, 2000; Sheldon \& Lyubomirsky, 2006). As positive psychology intervention research matures, we may be able to characterize individuals who do not respond to typical interventions, and pursue development of interventions that make use of their preferred modalities, emotions, or individual strengths. The ultimate goal would be to combine our current one-size-fits-all interventions into a repertoire of targeted techniques that, together, can provide coverage for a broad range of preferences and needs.

A discussion of the full range of positive psychology interventions, or even the subset of PE interventions, is beyond the scope of this article (for a review, see Sin \& Lyubomirsky, 2009). A few of the prominent distinctions are between reflection and overt behavior, between self-focus and other-focus, and among different PEs. For example, a count your blessings intervention is reflective, relatively self-focused, and likely to be associated largely with gratitude, contentment, or both. The gratitude letter intervention is very similar, but because participants actually write (and may even deliver) a letter to a specific person, it becomes more behavioral and highly other-focused. The imagine your best possible self exercise is similar to count your blessings, but involves emotions, such as pride and interest rather than gratitude; an act of kindness intervention resembles the more behavioral, otherfocused gratitude letter, but involves emotions, such as compassion, love, and trust. To the extent that each of these interventions is a means of self-generating PEs, we suggest that they would each broaden people's awareness and build their resources, including resources that would support long-term behavioral maintenance.

\section{Building and maintaining resources}

The data were consistent with the hypothesis that increased resources endure even for those who cease meditating. As predicted by the broaden-and-build theory, resources built through 
PEs endured even after the ostensible source of the PEs was removed. However, we view this finding as tentative. Because participants who built resources were more likely to continue meditating - a reasonable choice from their own perspective - there were relatively few in whom we were able to assess post-meditation resource levels. Additionally, because participants who stopped meditating often retained their increases in PEs (see below), we cannot rule out the possibility that continued PEs are required to maintain resources, even if continued meditation is not.

We found the same pattern for PEs as for resources: Participants who ceased to meditate maintained any increases in PEs they had developed while meditating. At first blush, this may not appear consistent with a straightforward view of the broaden-and-build theory, which views PEs as transient, situational phenomena. If meditation practice was the cause of participants' increased PEs, the PEs should have stopped at the same time the meditation did. However, the broaden-and-build theory also states that enduring resources can become sources of PEs (Fredrickson \& Joiner, 2002), as they help people successfully deal with life's challenges and appreciate its pleasures. To illustrate this upward spiral dynamic, a participant who experienced an increase in optimism or trust might have become able to forgive a longstanding grudge or make a risky personal disclosure to a friend. As a result, they might build resources, such as increased peace of mind or a stronger friendship. Even if the original source of PEs is taken away (i.e., if the participant stops meditating), these new resources can continue to generate PEs. This feedback cycle between PEs and resources offers a mechanism by which gains in PEs might be sustained. Future research may benefit from determining more about how participants' lives have changed post-intervention, even in domains that have little to do with the specific domain of the intervention.

\section{Potential effects of observation}

By the time of follow-up, all participants had been offered LKM training. Thus, condition assignment was not an initial focus of follow-up investigation. However, we observed a very strong effect on participation in training. All participants initially expressed interest in learning about meditation, yet only $54 \%$ of waitlist participants attended three or more workshop sessions, compared to $96 \%$ of experimental participants. It is possible that waitlist participants lost interest over time, or that there were environmental or seasonal issues they faced that experimental participants did not. However, it is also possible that experimental participants were encouraged to remain engaged by receiving frequent questionnaires and by their impression that their data were contributing to science. It may be valuable for future research to maintain at least occasional contact with waitlist participants, which could maintain engagement as well as generating additional data on the intervention.

\section{Differences from past work}

In our original report on the LKM intervention (Fredrickson et al., 2008), we observed that individuals in the meditation condition had lower average PE levels than control participants at baseline and during the first week of training. We speculated that participants may have been uneasy about the effort that would be required (they already knew their condition assignment at baseline), and that it took them 1-2 weeks of effort to become skilled enough to find LKM rewarding. However, at follow-up, we found that those who continued to meditate more than 1 year later had not shown this pattern, suggesting that our earlier interpretation was incorrect. Depressed or unchanging levels of PEs during the early weeks of practice instead pointed to individuals who were less likely to continue meditating, and may suggest that they would benefit from additional assistance, or from moving to a different intervention. 
We also discovered that our follow-up sample differed from the original sample in terms of PEs over the course of the intervention. Follow-up respondents who had been in the experimental (meditation) group had experienced more PEs than experiment-group participants who did not respond to the follow-up. In contrast, follow-up respondents from the waitlist control group were lower on PEs than non-respondents from that group. We find these results difficult to interpret, but they do suggest that our findings may not generalize to the entire sample of original participants. Because of this, as well as the findings reported in the following section, we encourage other investigators to test for differences in baseline characteristics when assembling follow-up samples.

\section{The functions of early PEs in long-term practice}

We observed evidence that baseline PEs predicted continued meditation. It may be that LKM is more appealing to dispositionally positive individuals, but it is also possible that baseline PEs provided participants with additional energy, optimism, or willingness to experiment, helping them generate interest in LKM and apply its principles in their lives. It is even possible that an additional, unrelated PE induction at the beginning of training could increase adherence and retention, leading to better and more lasting results. Future research could easily explore whether participants' responsiveness to PE skill interventions is improved by `supplementary' PEs, from straightforward inductions, such as humor, small gifts, or self-affirmations.

Additionally, participants were much more likely to continue meditating more than a year later, if they experienced a rapid PE response when they began LKM training. This is not due to differences in effort; non-continuers practiced and attended classes as diligently as continuers. Nor is it simply a proxy for whether they were capable of doing LKM: during the final weeks of the intervention, the non-continuers began to show a positive emotional response similar to the continuers. We propose the following three possible explanations, with comments on how each could be investigated.

Appropriateness of the intervention-First, it may be that an early PE response indicates a better person-activity fit, which is known to predict continued practice of other PE skills (Lyubomirsky, Dickerhoof, Boehm, \& Sheldon, 2008). Less responsive participants may have had no problem complying with prescribed practice, but lacked the intrinsic motivation to continue meditating later on. This explanation could be tested in a multi-component longitudinal study that involves practicing several PE activities for several weeks each. It would predict that, first, individuals would differ from one another in the amount of practice required for a given activity to evoke PEs, and second, individuals would be most likely to continue to practice the activities that evoked PEs early on.

Trait PE reactivity-Second, the difference in response may have reflected variation in an underlying trait of PE reactivity. In this case, the participants with a rapid response to LKM would have had a similarly rapid response to many other PE activities. This is a special case of the previous model, with the additional prediction that individuals would appear to be 'early responders' or 'late responders' across the board, rather than showing relatively rapid response to some activities and relatively slow response to others. Unfortunately, it would also mean that individuals who showed a slow response to one intervention would be unlikely to fare better with a different one. Interventions aimed at slow responders might benefit from additional components emphasizing the importance of persistence, or drawing attention to benefits of practice other than subjective PEs.

A 'critical mass' of PEs-Third, at the end of the intervention period, continuing meditators showed a much greater elevation of PEs than non-continuers did (because non- 
continuers were 'late responders,' their emotions had not spent as much time on an upward trajectory; see Figure 1). We speculated earlier that those with high PE levels at baseline may have had more flexibility or resources to devote to learning meditation, and the same may have been true at the end of the study: Those with higher PEs when the meditation workshop and study ended may have been more likely to make the life changes required to continue meditating without the structure of daily reporting and weekly workshops. A simpler possibility is that those whose PEs had increased more had stronger personal evidence that meditation was worth the effort.

This third model implies that early versus late response is not of central importance; if the study had continued until week 13, late responders would have reached the same level of PE that early responders reached on week 8 , and would have shown the same level of continued practice. The LKM intervention in our original study did not continue long enough to test this hypothesis, but it could be easily explored in any study that did last long enough for late responders to show substantial increases in PEs. If it is true that continued practice is predicted by the participant's total progress, rather than by the speed of their response, it would suggest that even very slow responders can gain long-lasting benefits from positive psychology interventions. They simply require more sustained or intensive training before they can be left to practice on their own.

In contrast to our findings about PEs, our hypothesis that initial resources would predict continued meditation was not supported. Individuals who continued to meditate were not initially higher on resources, such as resilience, mindfulness, or relationship closeness. Although this means that we did not learn about traits or abilities associated with successful meditation practice, it does suggest that the LKM intervention - and perhaps positive psychology interventions in general - can be broadly applicable and can help build resources even for participants who are not unusually gifted (or unusually impaired) to begin with.

\section{Limitations}

This study has a number of weaknesses: Only about half of the original participants responded, and the lack of post-meditation assessments for the waitlist group prevented the use of those participants in analyses of change over time. Our tests of the importance of PEs early in training were post-hoc, and we were unable to definitively test the hypothesis that resources would be maintained when meditation ceased. In contrast, our core hypotheses were clearly supported: participants continued meditating, and meditation remained associated with increased PEs.

We observed that at follow-up, participants who continued meditating reported more PEs than those who had ceased meditating, or had never meditated. This could indicate that meditation continued to evoke PEs for these participants, or that participants with higher levels of PEs were more likely to maintain a meditation practice. Differentiating these hypotheses is challenging: continuing meditation is an individual difference, and can neither be randomly assigned nor measured in a control group that has not been offered meditation training. One option for future studies would be to randomly assign a subset of continuing meditators to refrain from meditating for several days. This would require high participant retention through the follow-up period, as well as continuing commitment and interest on the part of participants, so researchers who may want to investigate this type of question would do well to plan on it from the study's inception.

Future studies will also benefit from more frequent follow-up assessments. These will bolster retention, provide multiple post-treatment assessments for waitlist control participants, and provide information about participants who continued meditating for periods shorter than 1 year. Frequent follow-ups may also act as reminders or boost 
motivation to continue (or resume) meditation. One benefit of this study's unannounced 15month follow-up is that it better approximates the experience of individuals who learn these skills outside a research context, and allows the strong conclusion that many participants continue to meditate even with a complete lack of formal structure and no belief that they will be asked to report on their behavior in the future. This contrasts with the low workshop attendance among waitlist participants, which, we speculate, suggests that formal structure may be valuable while first learning the skills.

\section{Conclusions}

This is one of the first and most detailed long-term follow-ups to a positive psychology intervention, and provides new evidence on the role of PEs in long-term behavioral maintenance and the continued effectiveness of skills for generating them. The results are very encouraging for the field: We found that working adults will continue to use skills taught in a positive psychology intervention, and that at least one such skill, meditation, remains enjoyable and potentially beneficial over the course of a year.

Our finding that early PE reactivity predicts intervention effectiveness has the potential to be particularly important. It suggests that, consistent with the broaden-and-build theory, positive emotions help support efforts to change one's life and acquire new skills. This could be especially valuable in an intervention context, in which simple and seemingly extraneous PE inductions could jumpstart participants' appreciation for and readiness to apply the skills being taught. We encourage future positive psychology intervention researchers to experiment with including simple and transient PE inductions (e.g., humorous films, candy) early in training for a subset of their participants. This is likely to help, unlikely to interfere with the intervention, and can test whether the relationship between early PEs and intervention effectiveness is indeed causal.

The finding that rapid PE response predicted continued meditation may also have important implications for positive psychology intervention practice. If nothing else, it could prevent a participant from spending weeks or months on a practice that is unlikely to be effective, freeing them to search for one that is a better personal fit. Future research may also find that the actual predictor of continued meditation is the level of PEs at the end of the intervention, which is correlated but not fundamentally associated with speed of response. If so, then intervention providers could recommend longer periods of structured training for participants with slower PE responses. This would allow them to reach the same level of PEs as other participants, before moving on to voluntary, self-paced practice.

In sum, this study provided valuable information about the mechanisms behind one PE intervention and its long-term effectiveness. It provides good reason to perform more frequent and in-depth follow-ups in future studies, and we hope that other researchers will join us in observing how positive psychological skills like LKM transition from techniques learned in a formal intervention to organic parts of participants' lives.

\section{Acknowledgments}

This study was supported by the National Institute of Mental Health grant MH59615. The authors thank their colleagues John Kraemer and John Eargle for statistical advice and Elizabeth Bartmess and Kathryn Irish for comments on the manuscript.

\section{References}

Aron A, Aron EN, Smollan D. Inclusion of other in the self scale and the structure of interpersonal closeness. Journal of Personality and Social Psychology. 1992; 63:596-612. 
Block J, Kremen AM. IQ and ego-resiliency: Conceptual and empirical connections and separateness. Journal of Personality and Social Psychology. 1996; 70:349-361. [PubMed: 8636887]

Brown KW, Ryan RM. The benefits of being present: Mindfulness and its role in psychological wellbeing. Journal of Personality and Social Psychology. 2003; 84:822-848. [PubMed: 12703651]

Bryant F. Savoring Beliefs Inventory (SBI): A scale for measuring beliefs about savouring. Journal of Mental Health. 2003; 12:175-196.

Cohn, MA.; Fredrickson, BL. Positive emotions. In: Snyder, CR.; Lopez, SJ., editors. Handbook of positive psychology. 2nd ed.. Oxford University Press; New York: 2009. p. 13-24.

Cohn MA, Fredrickson BL, Brown SL, Mikels JA, Conway AM. Happiness unpacked: Positive emotions increase life satisfaction by building resilience. Emotion. 2009; 9:361-368. [PubMed: 19485613]

Deci EL, Ryan RM. Target article. The 'what' and 'why' of goal pursuits: Human needs and the selfdetermination of behavior. Psychological Inquiry. 2000; 11:227-268.

Diener E, Emmons RA, Larsen RJ, Griffin S. The satisfaction with life scale: A measure of life satisfaction. Journal of Personality Assessment. 1985; 49:1-5.

Diener E, Lucas RE, Scollon CN. Beyond the hedonic treadmill: Revising the adaptation theory of well-being. American Psychologist. 2006; 61:305-314. [PubMed: 16719675]

Elliot AJ, Sheldon KM. Avoidance personality goals and the personality-illness relationship. Journal of Personality and Social Psychology. 1998; 75:1282-1299. [PubMed: 9866188]

Emmons RA, McCullough E. Counting blessings vs. Budrens: An experimental investigation of gratitude and subjective well-being in daily life. Journal of Personality and Social Psychology. 2003; 84:377-389. [PubMed: 12585811]

Epping-Jordan JE, Compas BE, Osowiecki DM, Oppedisano G, Gerhardt C, Primo K, Krag DN. Psychological adjustment in breast cancer: Processes of emotional distress. Health Psychology. 1999; 18:315-326. [PubMed: 10431932]

Fredrickson BL. What good are positive emotions? Review of General Psychology. 1998; 2:300-319.

Fredrickson BL. The role of positive emotions in positive psychology: The broaden-and-build theory of positive emotions. American Psychologist. 2001; 56:218-226. [PubMed: 11315248]

Fredrickson BL, Cohn MA, Coffey K, Pek J, Finkel SM. Open hearts build lives: Positive emotions, induced through meditation, build consequential personal resources. Journal of Personality and Social Psychology. 2008; 95:1045-1062. [PubMed: 18954193]

Fredrickson BL, Joiner T. Positive emotions trigger upward spirals toward emotional well-being. Psychological Science. 2002; 13:172-175. [PubMed: 11934003]

Fredrickson BL, Kahneman D. Duration neglect in retrospective evaluation of affective episodes. Journal of Personality and Social Psychology. 1993; 65:45-55. [PubMed: 8355141]

Fredrickson BL, Tugade M, Waugh CE, Larkin G. What good are positive emotions in crises? A prospective study of resilience and emotions following the terrorist attacks on the United States on September 11th, 2001. Journal of Personality and Social Psychology. 2003; 84:365-376. [PubMed: 12585810]

Harker L, Keltner D. Expressions of positive emotion in women's college yearbook pictures and their relationship to personality and life outcomes across adulthood. Journal of Personality and Social Psychology. 2001; 80:112-124. [PubMed: 11195884]

Keyes CLM. Social well-being. Social Psychology Quarterly. 1998; 61:121-140.

Keyes CLM. Mental health in adolescence: Is America's youth flourishing? American Journal of Orthopsychiatry. 2006; 76:395-402. [PubMed: 16981819]

Levy BR, Slade MD, Kunkel SR, Kasl SV. Longevity increased by positive self-perceptions of aging. Journal of Personality and Social Psychology. 2002; 83:261-270. [PubMed: 12150226]

Lyubomirsky, S.; Dickerhoof, R.; Boehm, JK.; Sheldon, KM. How and why do positive activities work to boost well-being? An experimental longitudinal investigation of regularly practicing optimism and gratitude. 2008. Manuscript under review

Lyubomirsky S, Sheldon KM, Schkade DA. Pursuing happiness: The architecture of sustainable change. Review of General Psychology. 2005; 9:111-132. 
Markland, AL.; Pressman, SD.; Cohen, S. Positive affect and immune function. In: Ader, R., editor. Psychoneuroimmunology. 4th ed.. Academic Press; New York: 2006. p. 771-779.

Moskowitz JT, Epel ES, Acree M. Positive affect uniquely predicts lower risk of mortality in people with diabetes. Health Psychology. 2008; 27:S73-S82. [PubMed: 18248108]

Moskowitz JT, Folkman S, Acree M. Do positive psychological states shed light on recovery from bereavement? Findings from a 3-year longitudinal study. Death Studies. 2003; 27:471-500. [PubMed: 12814129]

Moskowitz, JT.; Hult, JR.; Duncan, LG.; Cohn, MA.; Maurer, S.; Bussolari, C.; Acree, M. A positive affect intervention for people experiencing health-related stress: Development and pilot testing. under review

Ong AD, Allaire JC. Cardiovascular intraindividual variability in later life: The influence of social connectedness and positive emotions. Psychology and Aging. 2005; 20:476-485. [PubMed: 16248706]

Parducci, A. Happiness, pleasure, and judgment: The contextual theory and its applications. Lawrence Erlbaum; New York: 1995.

Ryan RM, Deci EL. Self-determination theory and the facilitation of intrinsic motivation, social development, and well-being. American Psychologist. 2000; 55:68-78. [PubMed: 11392867]

Ryff CD. Happiness is everything, or is it? Explorations on the meaning of psychological well-being. Journal of Personality and Social Psychology. 1989; 57:1069-1081.

Seligman MEP, Rashid T, Parks AC. Positive psychotherapy. American Psychologist. 2006; 61:774788. [PubMed: 17115810]

Seligman MEP, Steen T, Park N, Peterson C. Positive psychology progress: Empirical validation of interventions. American Psychologist. 2005; 60:410-421. [PubMed: 16045394]

Sheldon KM, Lyubomirsky S. How to increase and sustain positive emotion: The effects of expressing gratitude and visualizing best possible selves. The Journal of Positive Psychology. 2006; 1:73-82.

Sin NL, Lyubomirsky S. Enhancing well-being and reducing depressive symptoms with positive psychology interventions: A practice-friendly meta-analysis. Journal of Clinical Psychology: In Session. 2009; 65:467-487.

Snyder CR, Harris C, Anderson JR, Holleran SA, Irving LM, Sigmon ST, Harney P. The will and the ways: Development and validation of an individual-differences measure of hope. Journal of Personality and Social Psychology. 1991; 60:570-585. [PubMed: 2037968]

Spanier GB. Measuring dyadic adjustment: New scales for assessing the quality of marriage and similar dyads. Journal of Marriage and the Family. 1976; 38:15-28.

Tkach, C.; Lyubomirsky, S. Unlocking the treasury of human kindness: Enduring improvements in mood, happiness, and self-evaluations. University of California; Riverside, CA: 2005.

Tkach, C.; Lyubomirsky, S. Spicing up kindness: The role of variety in the effects of practicing kindness on improvements in mood, happiness, and self-evaluations. 2007. Unpublished manuscript

Waugh CE, Fredrickson BL. Nice to know you: Positive emotions, self-other overlap, and complex understanding in the formation of a new relationship. Journal of Positive Psychology. 2006; 1:93106. 


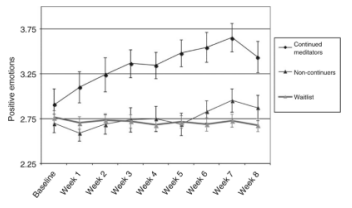

Figure 1.

Early positive emotional reactivity to the intervention predicts continued meditation. 
Table 1

List of resources assessed and measures used.

\begin{tabular}{|c|c|c|c|c|}
\hline Name & Construct & Sample item(s) & Number of items & Alpha \\
\hline $\begin{array}{l}\text { Mindfulness and } \\
\text { Awareness Scale } \\
\text { (MAAS; Brown \& } \\
\text { Ryan, 2003) }\end{array}$ & $\begin{array}{l}\text { Mindful awareness (all items } \\
\text { reverse-scored) }\end{array}$ & $\begin{array}{l}\text { 'I could be experiencing some } \\
\text { emotion and not be conscious of it } \\
\text { until some time later' }\end{array}$ & 15 & 0.92 \\
\hline $\begin{array}{l}\text { Psychological and social } \\
\text { well-being }{ }^{a}(\mathrm{PWB} / \\
\text { SWB; Keyes, 2006) }\end{array}$ & Indicators of flourishing & $\begin{array}{l}\text { 'Over the past month, how often... } \\
\text { did you feel that you were good at } \\
\text { managing the responsibilities of your } \\
\text { daily life? (PWB) did you feel that } \\
\text { you belonged to a community (like a } \\
\text { social group, your neighborhood, } \\
\text { your city)? (SWB)' }\end{array}$ & 14 & $\begin{array}{l}\mathrm{PWB}=0.86 \\
\mathrm{SWB}=0.89\end{array}$ \\
\hline $\begin{array}{l}\text { Agency thinking } \\
\text { (Snyder et al., 1991) }\end{array}$ & Sense of self-efficacy & 'I meet the goals I set for myself.' & 5 & 0.83 \\
\hline $\begin{array}{l}\text { Pathways thinking } \\
\text { (Snyder et al., 1991) }\end{array}$ & $\begin{array}{l}\text { Ability to find multiple routes to } \\
\text { a goal }\end{array}$ & $\begin{array}{l}\text { 'There are lots of ways around any } \\
\text { problem.' }\end{array}$ & 5 & 0.77 \\
\hline $\begin{array}{l}\text { Ego resilience (ER89; } \\
\text { Block \& Kremen, 1996) }\end{array}$ & $\begin{array}{l}\text { Ability to bounce back from } \\
\text { adversity and adapt to shifting } \\
\text { demands }\end{array}$ & $\begin{array}{l}\text { 'I quickly get over and recover from } \\
\text { being startled.' 'I like to do new and } \\
\text { different things.' }\end{array}$ & 14 & 0.82 \\
\hline $\begin{array}{l}\text { Savoring Beliefs } \\
\text { Inventory (SBI; Bryant, } \\
\text { 2003) }\end{array}$ & $\begin{array}{l}\text { Ability to appreciate past, } \\
\text { present, and future experiences }\end{array}$ & $\begin{array}{l}\text { 'It's easy for me to rekindle the joy } \\
\text { from pleasant memories.' }\end{array}$ & 24 & 0.95 \\
\hline $\begin{array}{l}\text { Dyadic Adjustment } \\
\text { Scale (DAS; Spanier, } \\
\text { 1976) }\end{array}$ & $\begin{array}{l}\text { Social support given and } \\
\text { received }\end{array}$ & $\begin{array}{l}\text { 'On the whole, how much do your } \\
\text { friends and relatives make you feel } \\
\text { loved and cared for?' }\end{array}$ & 4 & $\begin{array}{l}\text { Only two items } \\
\text { per scale }\end{array}$ \\
\hline $\begin{array}{l}\text { Inclusion of other in self } \\
\text { (IOS; Aron, Aron, \& } \\
\text { Smollan, 1992) }\end{array}$ & $\begin{array}{l}\text { Perceived overlap between } \\
\text { oneself and close other }\end{array}$ & $\begin{array}{l}\text { Participant chooses one of seven } \\
\text { diagrams representing increasing } \\
\text { degrees of overlap between oneself } \\
\text { and the target. }\end{array}$ & 1 & Only one item \\
\hline $\begin{array}{l}\text { Illness symptoms (Elliot } \\
\text { \& Sheldon, 1998) }\end{array}$ & $\begin{array}{l}\text { Symptoms of illness or poor } \\
\text { health (reversed to yield a } \\
\text { 'health' score) }\end{array}$ & $\begin{array}{l}\text { 'In the past month, how often have } \\
\text { you had... } \\
\text { Headaches? } \\
\text { Chest pain? } \\
\text { Congestion?' }\end{array}$ & 13 & 0.87 \\
\hline $\begin{array}{l}\text { Satisfaction with Life } \\
\text { Scale (SWLS; Diener, } \\
\text { Emmons, Larsen, \& } \\
\text { Griffin, 1985) }\end{array}$ & Overall life satisfaction & $\begin{array}{l}\text { 'So far I have gotten the important } \\
\text { things I want in life.' }\end{array}$ & 5 & 0.88 \\
\hline
\end{tabular}

Notes:

${ }^{a}$ Assessments from T1 and T2 used a longer version of the PWB and SWB measures (Keyes, 1998; Ryff, 1989) with 61 additional items. The brief version measured all the same constructs, with internal consistency comparable to the longer version. We converted all PWB and SWB scores to $z$ scores in order to perform comparisons among timepoints. 